\title{
Impact of Globalisation and Affordable Housing Provision
}

\author{
Abel Owotemu ${ }^{1}$, Cross Ogohi Daniel ${ }^{2}$ \\ ${ }^{1}$ Department of Business Administration, \\ Faculty of Management Sciences, \\ Nile University of Nigeria,

\begin{abstract}
The challenge of affordable housing has assumed global proportions, and the various efforts at private and public sector levels is yet to put a significant dent in what is becoming a worldwide epidemic with economic, social and environmental implications. In terms of strategies, public-private partnerships (PPP's) as a solution have grown in popularity on an equally global scale. In evaluating the extent of affordable housing as a global issue, this paper aims to evaluate the factors that were commonly administered in the application of PPPs as an effective strategy for addressing affordable housing. This paper notes that while the issue of affordable housing may be global, proposing PPP's as a silver bullet may well depend on contextual peculiarities and may yield differences in affordable housing delivery outcomes. The study notes that while lending practices, land laws and incomes levels are critical factors in determining delivery of affordable housing, other factors like proper allocation of risk, socio-political stability, and quality standards (regulations) are also significant factors that influence successful affordable PPP housing strategies in the broader context.
\end{abstract}

Keywords---- Public-private partnership; Affordable Housing Delivery, Strategy

\section{INTRODUCTION}

The global affordable housing is best described by the Chinese philosophy of finding opportunities in crises. According to Chan (2018) and other investments analysts, Affordable housing possesses the potential to create large scale opportunities for the housing finance, construction and infrastructure industries on a global scale.

Charles et al. (2019), estimates that in view of the demand, providing affordable housing across the worlds cities and regions represents $\$ 2.3$ trillion investment opportunity with the potential to add an estimated $10 \%$ or the equivalent of \$200-\$250 million to global gross domestic product between 2020-30 (excluding estimates from job creation and poverty eradication that typically characterises construction and housing industries in emerging and developed markets).

Affordable housing has gone beyond being a buzzword or political statement according to the World bank group (2018) affordable housing under the Sustainable Development Goals (referenced as SDG 11) is considered a global issue.

The World Bank's SDG atlas notes that the provision of what it terms affordable, adequate, safe, accessible and sustainable housing is a target issue that most countries and governments are mandated to resolve by the year 2030.

According to Clegg (2018) and Woetzel (2014) as well as other practitioners, Affordable Housing has been considered across emerging and developed countries as a fundamental requirement to lead a healthy and functional economic life.

However, the ability to attain affordable housing remains an elusive goal on a global scale in view of global trends like Urbanisation, Population growth and Income Inequality. The ability of individuals to access and pay for decent accommodation will globally impact over two billion individuals with a reasonable number in sub-Saharan Africa and Nigeria.

According to scholars and PPP practitioners like Davie (2015) and Bielenberg et al (2016), the concept of Public private partnerships takes its root from private financing initiatives aimed at providing services or solutions for which government may typically not have the budgetary allocation to cater for as part of its responsibilities toward citizens. 
Housing as a basic human need falls into this category of services that governments across the world have had challenges in providing. According to scholars like Kadiri (2018), the intentions of providing Housing for all Nigerians was part of the country's responsibilities under the millennial and sustainable development goals of various governments as part the policies promoted on the back a globalisation trend and policy benchmark for globally holding government accountable for their citizens.

\section{LITERATURE REVIEW}

The McKinsey Institute (2014) have noted that, there has been a lack of commitment on the side of government to actualize the dream of social and physical infrastructure. According to Kadiri (2018), taking a cursory look at cities where population density and housing needs are at their highest across the world, reveals various degrees and levels of housing deficits.

Given the backdrop of growing macroeconomic challenges and uncertainty, UNCTAD (2018) and Price Water House Coopers (2019) have noted that administrative experience in recent times has consisted of an overdependence on Government earnings from natural resources and foreign borrowings as the major source of finance (evident in the growing levels global fiscal deficit, interest rate volatility and social instability that ensues occasionally with implications for poor infrastructural development and slow economic growth and development).

According to Dominic et al (2015) and Vallee (2018), Public Private Partnership as a practice has become popular on the global stage. The growth of Public private partnerships is linked to the insufficient funds available to government for financing numerous development projects (including Housing) as well as governments poor risk management Capacity.

As per the Centre for Affordable housing (2019), the noted challenges to government financing and its impact on a nation's development, has increased the prospects of Public Private Partnerships as an alternative to delivery of infrastructure and housing.

Also, according to Parashar (2014) the drive towards Public Private Partnerships connotes the willingness of capital in private hands to be invested in solving major socio-economic challenges like providing affordable housing.

The Centre for affordable Housing in Africa (2018) has noted that the challenge is particularly severe in emerging economies of the world, where over 200 million households dwell unplanned settlements. In terms of degrees, about 10 major urban centres play host to about $60 \%$ of the world's stock of substandard housing as detailed in figure 1 below;

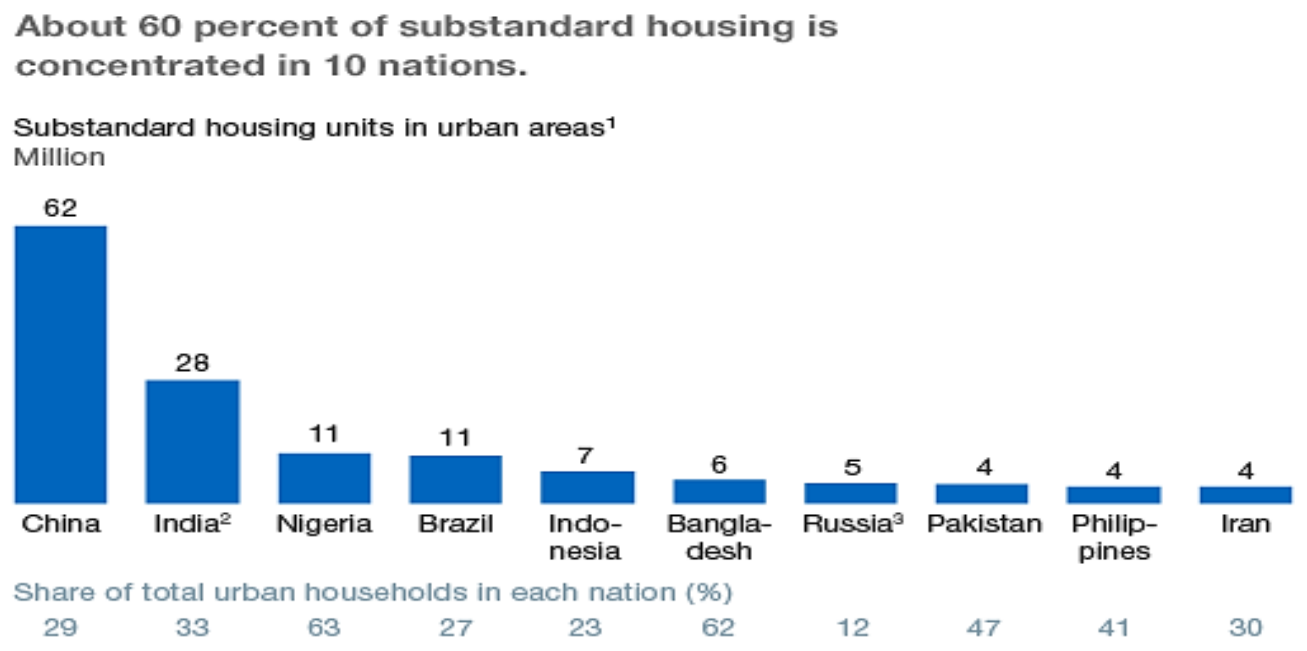

Figure 1: Graphical analysis of substandard Housing in different countries (Courtesy McKinsey, UN SDG Indicators)

According to findings by the United Nations development Programme (2017) and the Mckinsey Global Institute (2018) it has been estimated that over 300 million households in urban centres across the world are financially burdened by housing cost and by consequence live in substandard housing arrangements. 
Chan (2018) also estimates that by year 2025, that the estimates for substandard housing and households with housing affordability issues will account for a third of global population. In a similar vein, Shi et al (2016) and Lohr (2017) as well as others have noted that advanced economies just like their emerging market counterparts have not been spared from the challenges of affordable housing.

According to Chan (2018) and Clegg (2018) over 60 million households in advanced economies are facing financial challenges linked to housing costs. These scholars further note that at least 35 million families occupy crowded, unsanitary and environmentally inadequate housing.

In terms of examples Chan (2018) notes that within the European Union, 5\% of households cohabit in substandard and overcrowded accommodations. While in Japan Chan (2018) notes that $8 \%$ of Japanese households are living in housing that do not meet United nations acceptable standards for housing while the United States of America has about $2 \%$ of its over 300 million population living in substandard housing.

Also, data from centre for Affordable Housing (2019) and the world economic forum (2019) notes in terms of the global affordability gap, there is a void of over $\$ 600$ Billion Dollars accounting for the differential between income available for housing and the market price of a standard housing units on a yearly basis or the equivalent of a percentage point of global GDP.

While for least affordable cities like Mumbai and Lagos, this gap is over 10\% of local GDP as more than 90\% of households cannot afford housing at market prices as indicated in figure 2 below;

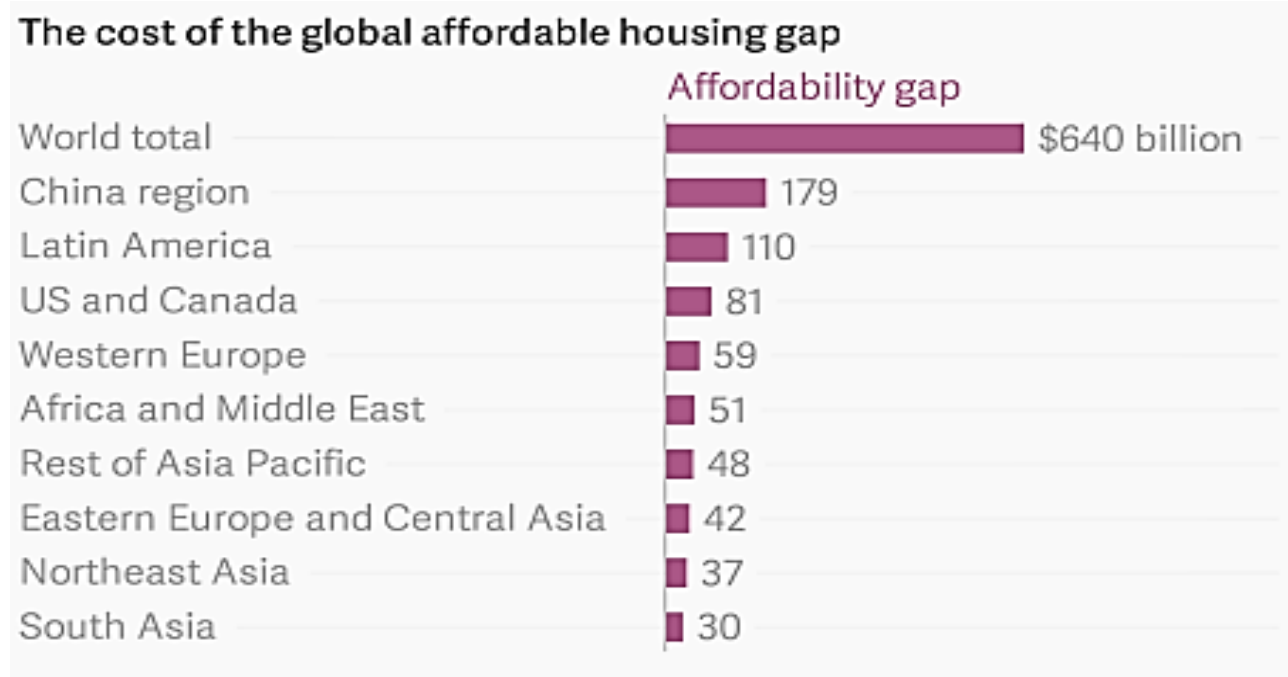

Figure 2: Graphical analysis of Affordable Housing Gap in different regions (Courtesy McKinsey, UN SDG Indicators)

According to Kavishe et al., (2018) and Muhammed and Johar (2019) to address the issue of affordable housing numerous public-private partnerships are targeting providing over 400 million units of housing globally with an attendant cost outlay of about $\$ 16$ trillion.

Scholars like Kwofie et al. (2016), Bielenberg (2016) Nweke (2017) and the McKinsey Global Institute (2014) have noted the importance and critical success achieved through PPP arrangements between the public sector and private sector.

In the studies Muhammed and Johar (2019) and Vallee (2018) noted that in terms of the success of PPP arrangements in delivering affordable housing, practitioners would need to be able to balance the contractual arrangements by ensuring factors like land is made available for development, ensure that construction costs are well priced, risk is mitigated through regulation and appropriate monitoring.

Also, scholars like Kjorstad (2016), Carter ( 2016) and Muhammed and Johar (2019) have also noted that in addition to providing land and financing, the use of innovative building materials, procurement and building design to provide cheaper 
housing are critical factors that are essential elements that make for a productive and successful PPP housing arrangement and not just the PPP arrangements in themselves.

Also, scholars like Kjorstad (2016), Rana and Izuwah (2018) have also noted that although the concept, process, and key principles of PPP are virtually identical, in terms of delivery of affordable housing the arrangements sometimes does not guarantee successful delivery of projects as aspects of the housing sector are specific to locations, policies and regulatory and legal constraints from one country to another.

According to Muhammed and Johar (2019), and Bielenberg et al., (2016) while certain factors are considered very critical for the success of PPP projects generally, the relative importance of the same factors may not be relevant under different conditions such as political uncertainty or where the reputation of developers for effective and qualitative delivery of affordable housing is not guaranteed, regulated or ascertained.

As per the works of Parashar (2014), Trangkanont and Charoenngam (2014) and Kavishe et al. (2018) the major drawback in literatures on the issue of global affordable housing PPP deliver focused heavily on the partnership based on the acceptance of risk in the PPP arrangement from the perspective of government agencies and private sector participants with little evaluation of the low-income beneficiaries or end-users of the projects.

\section{METHODOLOGY}

In conducting this research, a systematic review of the global issue of affordable housing and if adopting Public-Private Partnerships is an effective strategy for addressing the issue of housing affordability was carried out. The study adopts the "systematic quantitative assessment technique" (SQAT) developed by Pickering and Byrne (2013). The SQAT framework recommends five essential steps in conducting a useful systematic review. The steps and its application in respect of this study are highlighted and described in Table 1 below. The study involved a review of forty articles using seven (7) databases;

Table 1: Description and application of SQAT for the Study

\begin{tabular}{|c|c|c|}
\hline & Step & Application in the current study \\
\hline 1. & Define topic & PPP as an effective Strategy for Affordable Housing Delivery \\
\hline 2. & $\begin{array}{l}\text { Formulate } \\
\text { research questions }\end{array}$ & $\begin{array}{l}\text { The critical research question (s): } \\
\text { 1. How Effective is Public-Private Partnership as a Strategy for addressing the Delivery } \\
\text { of Affordable Housing? }\end{array}$ \\
\hline 3. & Identify keywords & $\begin{array}{l}\text { "Public-Private Partnership", "Empirical Evidence of Successful PPP Strategies", "Affordable } \\
\text { Housing", }\end{array}$ \\
\hline 4. & $\begin{array}{l}\text { Identify and } \\
\text { search databases }\end{array}$ & $\begin{array}{l}\text { 1. } 7 \text { databases utilised: Elsevier; Emerald; Springer; Taylor and Francis; Sage; JSTOR; and } \\
\text { Wiley; } \\
\text { 2. "All in title" search using three search combinations: } \\
\text { a. "PPP" + "Affordable Housing." } \\
\text { b. "PPP strategy" + "affordable housing delivery." } \\
\text { c. "Evidence of PPP Successes"+ "Challenges in Housing Delivery Challenges." }\end{array}$ \\
\hline 5. & $\begin{array}{l}\text { Read and assess } \\
\text { publications }\end{array}$ & $\begin{array}{l}\text { 1. Abstracts of research articles found was read to ensure that they were dealing with Public- } \\
\text { private partnership strategies, affordable housing delivery and critical success factors and } \\
\text { challenges in the delivery of affordable housing. } \\
\text { 2. No secondary sources, no reviewed conference articles, and No book chapters was included; } \\
\text { only peer-reviewed articles and empirical papers was identified and reviewed. }\end{array}$ \\
\hline
\end{tabular}


The SQAT study approach involves the systematic study or review and assessment of research papers in a bid to determine their importance in being selected for a study review process. The SQAT process for this study involved the review of journals and published peer-reviewed articles to determine their inclusion or exclusion as part of the study process, to ensure a high level of quality of research paper is developed (Pickering \& Byrne, 2013).

The SQAT methodology provided the basis for the research in terms of identifying the critical and main themes, in answering the research question, and for carrying out a literature review for gaps in the literature" (Pickering \& Byrne, 2013). The application of the SQAT for this study provided a simple, logical and easy to apply a method that could be repeated and replicated as a critical aspect and prerequisite of ensuring a systemic review.

Based on the need to widely evaluate the critical research question with regards to globalisation, affordable housing and PPP's within a more modern context for this study, the study sources were augmented with the analysis of professional and policy-focused research articles.

These additional sources were instrumental in gaining additional and critical insights of housing affordability and application of PPP's as global concepts in the context of using PPPs as an effective strategy for combating housing affordability.

\section{DISCUSSIONS AND SUGGESTIONS FOR FUTURE RESEARCH}

Parashar (2014) and Kavishe et al. (2018) have noted that the widespread adoption of PPP housing arrangements for affordable housing had focused on the idea of a government and private sector collaboration with the risk and return for all parties well evaluated.

This study was able to uncover the fact that housing affordability as a global issue is impacted by other factors that termed critical success factors (CSF's) and critical failure factors (CFF's) associated with failed affordable housing attempts through PPP's as per the works of Carter (2016), Muhammed and Johar (2019), Kavishe et al. (2018) and Triveno and Hamilton (2017).

\subsection{Critical Failure Factors \& Critical Success Factors in Affordable Housing PPP's}

According to Parashar (2014) and Muhammed and Johar (2019), research critical success/failure factors were made famous in the early 1960s and at inception, the focus was more on the failure factors than the success factors. However, due to the rise of capitalism globally, there was a shift in emphasizing failures to emphasizing more success factors.

According to Chan (2018) and Kjorstad (2016) project promoters became more uncomfortable to document project failures efforts for fear of loss of funding or stakeholder support and failures also became more synonymous with risk as opposed to being considered as learning opportunities.

Parashar (2014), Muhammed and Johar (2019) and the other scholars have noted that CFF's are deficiencies or defects that are associated with the failure of infrastructure and affordable PPP housing projects. Meanwhile, CSF's are factors that are considered as vital or contributes in a significant way to the success of affordable housing project delivery (Kavishe et al. (2018) and Kwofie et al. (2016).

According to Parashar (2014), Muhammed and Johar (2019) and Sheppard and Beck (2016), as well as other scholars, have noted that successes and failures in PPP related affordable Housing projects have been characterized by an interaction of critical success and critical failure factors.

In terms of the importance of CSF's and CFF's, Parashar (2014) and Muhammed Johar (2019) stated that these concepts became largely pivotal in determining the effectiveness of affordable housing PPP's and became widely adopted as a cornerstone of improved practices in project management. Also, CSF's and CFF's have become the basis for gathering best practice and lessons learned information on unsuccessful or successful affordable housing projects, allocate resources, and forecast performance, provided a framework for identifying risk, Kavishe et al., (2018), Muhammad and Johar (2019) and Chan (2018).

In terms of successful and failing factors, Vallee (2018) notes that the legal structures in most countries were more favourable in handling traditional project management and procurement and not quite suited for PPP's as such laws emphasized authoritarian project management structure, and this has resulted in aborted PPP and failed infrastructure projects including affordable housing PPP's. 
Bielenberg (2016) and Kjorstad (2016) have noted that the success of PPP arrangements goes beyond the typical requirements to allocate risk, negotiate finance which had also been the bane of PPPs.

This study also notes that affordable housing PPP arrangements had the reputation of being complex with a significantly large degree of stakeholders with varied interests and the ability to or inability to balance these interest including the need to ensure affordability is a prime factor for Affordable Housing PPP failures and or effectiveness, Lohr (2017) and Trangkanont and Charoenngam (2014).

\subsection{Findings and Recommendations in Combating Housing-Affordability}

According to Sheppard and beck (2016), Charles et al. (2019) and Charles and Guna (2019) affordable housing continues to be an issue on a global scale that also presents an opportunity for growth if approached with country and case specific PPP innovations.

The application of innovative approaches to affordable will depend on the ability of countries and governments to create well structure delivery systems. According to the Centre for Affordable Housing (2018), approaches to resolving affordable housing cannot rest in the hands of developers or products as such efforts would need to involve Policymakers, collaborating with the private sector and stakeholders to establish a detailed plan for specific localities and cities.

As per the works of Vallee (2018) and Charles et al. (2019), policy makers in each local setting are encouraged to adopt global standards for affordable housing PPP's but also ensure that a required minimum standard for housing is defined and well balanced to not discourage investors interested in the construction of affordable housing as such policy stance have exacerbated the issue more and pushed low-income households into unplanned settlements.

The Centre for affordable housing (2018) in their findings proposes that a more appropriate solution for affordable housing PPP's would require setting of standards that take into consideration the rising economic aspirations of affordable housing subscribers.

In support of Sheppard and beck (2016), Charles et al. (2019) and Charles and Guna (2019), other scholars have also alluded to the fact that in terms of affordable housing, a better solution is to set standards that reflect rising aspirations or what could be termed incremental housing.

Incremental Housing according to Centre for Affordable Housing (2018) is an affordable housing innovation that puts individuals on the "property ownership ladder" for example via the delivery of a basic one bedroom with essential facilities like kitchen, bathroom and toilet and could be expanded into more bedrooms as income levels improve or social needs e.g. increase in family size ( this is a particularly popular affordable housing strategy adopted in emerging markets like Africa and Asia). Also, as an addition to the recommendations on the efficacy of affordable housing PPP's the following suggestions could be considered for further research;

I. Use of Land Banks: as one of the most capital intensive inputs to affordable housing delivery, policy makers could consider securing land with titles acceptable to investors in targeted locations and held for large scale housing provision and PPP's and protected from real estate speculation but should be utilized in timely and equitable fashion.

II. Moving from Housing Construction to Manufacturing of Houses: Construction cost Reduction: the average cost of delivering affordable housing can be significantly reduced by the introduction and application of manufacturing techniques like value engineering, prefabricated methods and efficient procurement to construction. Manufacturing of housing has become the norm for emerging markets like China and Malaysia as means of keeping up with housing demand at faster rate and at a cheaper cost than traditional construction to meet population growth (this could also become a viable option country's like Nigeria with rapidly growing population).

III. Sustainable Housing Methods: provision of affordable housing also presents challenges with regards to cost of maintenance and environmental challenges. In terms of addressing these challenges and scaling up delivery, the adoption of green and sustainable building methods is part of the innovation that could be adopted to address affordability and housing deficit. Sustainable methods include the use of finishes that reduce water and electricity consumption with little or no maintenance cost as added advantage for affordable housing. 
IV. Financial Innovations: a critical aspect of affordable housing delivery is the issue providing financing at a sustainable cost for affordable housing developers and subscribers. The introduction of impact and sustainability focused investors and financier that would fund available projects and finance homebuyers at cost that is socially weighted and cheaper targeted at prospective low-income home buyers. Such interventions could also provide low interest mortgages. Policy makers can also consider interventions that would reduce the risk of default for financial institutions for lending to low income homeowners there making affordable housing less risky e.g. provision of purchase or payment guarantees for completed projects.

\section{CONCLUSION}

This evaluated the extent to which affordable housing was a global issue and discovered that it also presented a large-scale investment opportunity if structured appropriately. As with the works of Chan et al.(2018), Muhammed and Johar (2019) as well as Vallee (2019), this study reinforces the their findings that the effectiveness of PPP's as a strategy for combating affordable housing is subject to various factors that are instrumental in determining its failure or success.

The study also notes that PPP arrangements in themselves are not a one size fits all approach as the local conditions under which they are implemented as well as the stakeholders and policies in specific local context should be considered. In conclusion the study also highlights and recommends other affordable housing innovations that could be areas of focus for future studies in terms of the delivery of affordable housing.

The study, therefore essentially adds to the study of affordable housing as a global phenomenon with a huge opportunity with potential of being resolved through PPPs that structured with a clear understanding and input of specific local context (even though PPPs are similar there is no one size fits all approach when it comes to applying it to affordable housing).

\section{RECCOMEDATION}

Also, as an addition to the finding on the efficacy of affordable housing PPP's the following suggestions could be considered for further research;

I. Use of Land Banks: as one of the most capital-intensive inputs to affordable housing delivery, policy makers could consider securing land with titles acceptable to investors in targeted locations and held for large scale housing provision and PPP's and protected from real estate speculation but should be utilized in timely and equitable fashion.

II. Moving from Housing Construction to Manufacturing of Houses: Construction cost Reduction: the average cost of delivering affordable housing can be significantly reduced by the introduction and application of manufacturing techniques like value engineering, prefabricated methods and efficient procurement to construction. Manufacturing of housing has become the norm for emerging markets like China and Malaysia as means of keeping up with housing demand at faster rate and at a cheaper cost than traditional construction to meet population growth (this could also become a viable option country's like Nigeria with rapidly growing population).

III. Sustainable Housing Methods: provision of affordable housing also presents challenges with regards to cost of maintenance and environmental challenges. In terms of addressing these challenges and scaling up delivery, the adoption of green and sustainable building methods is part of the innovation that could be adopted to address affordability and housing deficit. Sustainable methods include the use of finishes that reduce water and electricity consumption with little or no maintenance cost as added advantage for affordable housing.

IV. Financial Innovations: a critical aspect of affordable housing delivery is the issue providing financing at a sustainable cost for affordable housing developers and subscribers. The introduction of impact and sustainability focused investors and financier that would fund available projects and finance homebuyers at cost that is socially weighted and cheaper targeted at prospective low-income home buyers. Such interventions could also provide low interest mortgages. Policy makers can also consider interventions that would reduce the risk of default for financial institutions for lending to low-income homeowners there making affordable housing less risky e.g. provision of purchase or payment guarantees for completed projects.

\section{REFERENCES}

Bielenberg, A.; et al., (2016): Financing change: How to mobilize private sector financing for sustainable infrastructure. Article from McKinsey Center for Business and Environment January 2016 
Carter, L.;(2016): Five secrets of success of Sub-Saharan Africa's first road PPP. Article from World Bank's Public Private Partnership $\mathrm{Blog}$

Centre for Affordable Housing Finance (2019): Africa Housing Finance Year book 2019 edition

Chan, E. J; (2018): Reducing the Affordable housing Gap. A research paper by Bank Negara and Cagamas Housing watch Centre

Charles, A., \& Guna, D., (2019): 10 Ways Cities are tackling the global affordable housing crises. World Economic Forum https://www.weforum.org/agenda/2019/06/10-ways-cities-are-tackling-the-global-affordable-housing-crisis/ (Accessed online $23^{\text {rd }}$ December 2019)

Charles, A., et al., (2019): Making Affordable Housing a Reality. World Economic Forum http://www3.weforum.org/docs/WEF_Making_Affordable_Housing_A_Reality_In_Cities_report.pdf (Accessed online $23^{\text {rd }}$ December 2019)

Clegg, L., (2018): The World Bank and the Globalization of Housing Finance: Bretton Woods Project Critical Voices on The World Bank and IMF, https://www.brettonwoodsproject.org/2018/07/world-bank-globalisation-housingfinance-mortgaging-development/ (accessed online 25 ${ }^{\text {th }}$ September 2019.

Copiello, S., (2015): Achieving affordable housing through energy efficiency strategy. Energy Policy, 85, $288-298$.

Dominic, C.M., et al., (2016): A Review of Public Private Partnership on some Development Projects in Nigeria. International Journal of Application or Innovation in Engineering \& Management (IJAIEM) Volume 4, Issue 3, March 2015 ISSN 2319 - 4847

Foster, V., (2016): Africa's infrastructure: Five years on. Article from World Bank's Public Private Partnership Research Publication

Ibimilua, A.F \& Ibitoye, O. A (2015): Housing Policy in Nigeria: An Overview American International Journal of Contemporary Research Vol. 5, No. 2; April 2015

International Monetary Fund (2017): Modest Growth Pickup in 2017, A research Publication by Projects IMF.

Kadiri, S.;(2018): Nigeria and the lack of affordable housing. Article from Stears Business Research Publication https://www.stearsng.com/article/nigeria-and-the-lack-of-affordable-housing

Kavishe, N., et al., (2018): Critical success factors in public-private partnerships (PPPs) on affordable housing schemes delivery in Tanzania: A qualitative study. Journal of Facilities Management, 17(2), 188-207.

Kjorstad, J.;(2016): The usual suspects: mitigating risks in African public-private partnerships. Article from World Bank’s Public Private Partnership Research Publication

Kwofie, T. E., et al., (2016): A critical success model for PPP public housing delivery in Ghana. Built Environment Project and Asset Management Journal , 6(1), 58-73.

Löhr, D., (2017): Sustainable housing: A ground lease partnership model. Land Use Policy, 60, 281-286.

Makinde, O., (2014): Housing delivery system need and demand. Environment, Development and Sustainability, 16(1), 49-69.

Muhammad, Z., \& Johar, F., (2019): Critical success factors of public-private partnership projects: a comparative analysis of the housing sector between Malaysia and Nigeria. International Journal of Construction Management, 19(3), 257-269.

National Bureau of Statistics (2018): Nigeria's GDP Report. Archived from the original on September 2016. Retrieved 22 December 2019

Olobo, C.; (2016): 6 Tips for plugging Africa's infrastructure gap through public-private partnerships. Article from World Bank's Public Private Partnership Research Publication 
Oosterveer,P., (2019): Is co-living an answer to the affordable housing crisis? www.weforum.org/agenda/2019/05/coliving-answer-affordable-housing-crisis/ (Accessed online on $24^{\text {th }}$ November 2019)

Parashar, D., (2014): The Government's role in private partnerships for urban poor housing in India. International Journal of Housing Markets and Analysis, 7(4), 524-538.

Pickering, C., \& Byrne, J., (2013): The benefits of publishing systematic quantitative literature reviews for PhD candidates and other early-career researchers. Higher Education Research \& Development. 33. 534-548. $10.1080 / 07294360.2013 .841651$.

Price Water House Coopers (2020): Global Economy Watch Predictions for 2020: globalization takes a backseat. Economic Research Report

Rana, F., \& Izuwah, C., (2018): Infrastructure \& Africa's development-the PPP imperative. Article from World Bank's Infrastructure and Public Private Partnership publication

Schmidtz, S.,(2017):The Economist Globalisation has marginalised many regions in the rich world. www.economist.com/briefing/2017/10/21/globalisation-has-marginalised-many-regions-in-the-rich-world (accessed online on 24th November 2019)

Sheppard, G., \& Beck, M., (2016): The Sustainability of Public Private Partnership in Ireland: A theoretical framework. 1-14. Paper presented at 5th Management Control Journal

Shi, W., et al., (2016): Affordable housing policy in China: New developments and new challenges. Habitat International, 54, 224-233.

Trangkanont, S., \& Charoenngam, C., (2014). Critical failure factors of public-private partnership low-cost housing program in Thailand. Engineering, Construction and Architectural Management, 21(4), 421-443.

Triveno, L., \& Hamilton, E., (2017): Three misconceptions in the way of better housing policies. Article from World Bank's Building Sustainable Communities Research publication

Ugochukwu, I. B., \& Chioma, M. I., (2015). Local building materials: affordable strategy for housing the urban poor in Nigeria. Procedia engineering, 118, 42-49.

UNCTAD (2018): World investment report: Investing in the SDGs: An action plan. New York and Geneva: United Nations Research Publication

Vallee, M.., (2018): PPP laws in Africa: confusing or clarifying? Article from World Bank's Infrastructure and Public Private Partnership Research Publication

Woetzel, J., et al. (2014) Tackling the Worlds Affordable Housing Challenge, McKinsey Global Institute https://www.mckinsey.com/featured-insights/urbanization/tackling-the-worlds-ffordable-housing-challenge (Accessed online 25th September 2019).

WorldBank Group (2018): Atlas of Sustainable development Goals. Research Publication Under World Development Indicators by the World Bank Group (www.data.worldbank.org/wdi/sdgs)

Yale Global online (2019): Climate Action: Sustainable Floating Cities. https://yaleglobal.yale.edu/content/climateaction-sustainable-floating-cities (accessed online 24th November 2019)

Yale Global Online (2019): Affordable Housing As Human Right - Analysis https://www.eurasiareview.com/22052019-affordable-housing-as-human-right-analysis/(Accessed $\quad$ online $\quad 24^{\text {th }}$ November 2019) 